\title{
Learning is like a lava lamp: The student journey to critical thinking.
}

\section{Abstract}

This paper explores the ways in which a university Foundation Degree programme supports undergraduate early years students to develop critical thinking, mindfulness and self-actualisation through their lived personal and professional experiences. It considers the impact of this on graduates employed within the Early Years sector. Findings inform future design of a University Foundation Degree programme situated within Early Childhood Education and Care (ECEC). As undergraduates, students engage in higherlevel learning aligned to their practice within the workplace. An interpretive Participatory Qualitative Research methodology is used to gather the views of 6 alumni who completed their studies in 2014. They participated in the research freely within ethical parameters approved by a university ethics committee. Findings revealed that the development of critical thinking is empowered by having a personal or professional impetus, which in the case of Early Years is the child as being at the heart of values based practice. This, with the inclusion of mindfulness, drives students to a sustainable deeper layer of thinking to achieve self-actualisation. Through the acquisition of critical thinking students have been subsequently able to take up positions of authority within the early years workforce.

\section{Early Years, Foundation Degree, Professional Practice, Critical Thinking, Mindfulness, Self-Actualisation \\ Introduction}

Higher Education programmes of professional development for Early Childhood Education and Care, (ECEC) are instrumental in facilitating the ability of practitioners to provide high-quality services and outcomes for children and families (Organisation for 
Economic Cooperation and Development (OECD) 2006; 2011; 2012). The Foundation degree was introduced in 2000 in order to widen participation and offer those students who would not traditionally attend university the opportunity to gain the graduate skills required by employers. (Quality Assurance Agency (QAA) 2010). The Foundation Degree in Early Years is a nationally recognised vocational university programme at levels 4 and 5 where students are engaged in higher-level learning within both the Higher Education institution and the workplace; the learning in one environment embedded to the other. Through a process where knowledge and experience are inter-related, high levels of skill are achieved (Sheridan et.al 2009). Design and content are influenced by guidance from the Quality Assurance Agency Higher Education (QAAHE 2015) and is expected to have an effect in promoting self-directed learning and reflection on professional action.

Foundation Degree programmes are also required to enable progression to a bachelor's degree with honours, with an expectation that course design will promote the professional and academic skills necessary to access that route. This involves students in supported instructional study, workplace engagement and self-directed learning and reflection, all of which are integrated elements of the programme (QAAHE 2015). Critical thinking binds these elements together in enabling students to solve problems posed by the discipline (Worsley and Lamond 2014). It enables practitioners to both acquire knowledge and to construct knowledge within their work environment in order to deal with complex issues; in effect, encouraging students to learn how to learn and develop higher order thinking (Reed, Callan and Smith 2012; Coffield et al. 2004). For the student such an approach means developing the ability to learn new things, be adaptable and negotiate (Walker and Reed 2016; Reed, Tyler and Walker 2015). Thus, for all sectors of higher education including Foundation Degrees, critical thinking has become a highly 
valued goal (Candy 1991; Phillips and Bond 2004). Gibbs (2000, 2002) argues the Foundation Degree as a vocational degree aimed to meet the needs of employers denies 'the moral and critical reasoning skills expected of higher education citizenship’ despite university being seen as a 'critical space' where criticality is the norm within teaching and learning (Barnett 1997). Gibbs (2000) points out that it is not the content of the curriculum that is important but how the academic community uses it to shape the future. To be successful in meeting the needs of the sector, teaching needs to go beyond the embedding of critical thinking skills into a curriculum to the development of a 'culture of inquiry’ where critical dispositions can flourish (Phillips and Bond 2004, 293). It is the aim of this small-scale research to discover how Foundation Degrees can embed critical thinking sustainably to influence practice beyond the degree.

\section{Critical Thinking and Higher Education}

There has been much written about the nature of critical thinking within Higher Education. Dewey (1933) argued that learning to think and reason are key goals of education. Since this time, critical thinking in differing forms has been at the forefront of achieving these. Barnett (1997) for example, argues this requires more than the development of operational critical thinking skills: it needs engagement in and with the world. He proposes an axial approach where narrow, operational critical thinking skills; critical thought, including reflexivity; the reconstructing of traditions and transformatory critique interacts with knowledge, self and world. This he aligns with critical reason, critical self-reflection and critical action. The dynamic interplay between these features are central to critical thinking and need to be fostered through an embedded culture of curiosity and inquiry. University, he argues, is a safe space where this can be developed. Critical thinking has been seen as an essential component of developing student autonomy, lifelong learning and self- directed learning (Brookfield, 1985; Mezirow 1985; 
Candy 1991; Knapper and Cropley 1991; Ramsden and Martin 1996). Kreber (1998) argues that over the years, different techniques and strategies for developing these skills have been proposed but that these have assumed that they will work equally well for all students. Consequently, educators have asked if these skills are developed by internal factors such as how you see yourself as a learner (Weiner, 1986), learning style (Kolb 1984) or how psychological type introduced by Jung (1971) can influence transformative learning (Cranton, 1994; Meizirow 1991).

More recently, the higher education agenda of maximising employability through study to meet the needs of increasing globalisation and market competition has aligned with the need to develop the ability to 'think well' and develop problem solving skills (Sedlak et al. 2003). This involves self- directed learning, asking questions and developing a body of knowledge and ability to argue ones' case. Added to this, the post- structuralist agenda highlights the importance of 'professional identities' which can be constructed and reconstructed through discourse (Stronach et al. 2002; Zembylas 2004) and include notions of how participants view their world and their life (MacNaughton 2000). In a rapidly changing field such as Early Years, changes in policy, legislation and practice and the need to acquire skills to manage these can result in ever changing discourses that impact on emerging professional identity (Ortlipp et al. 2011). The agenda for developing critical thinking has now included the need for an 'outside in' and 'inside out” self-sustaining and growth producing learning (Sheridan et al. 2009, 3). This may contribute to the delivery of high quality Early Years services through acquiring new knowledge and applying self-reflection, self- sustaining practices and goals. However, as Worsley and Lamond $(2014,49)$ assert within early years, critical thinking must be viewed as a process which 'encompasses the development of professional and personal features' which include academic rigour, learning how to think, work with others, communicate 
effectively and ethical practice. These attributes mirror those that educators strive for children to develop. In addition, the development of critical thinking encompasses critical reflection (the relationship between reflective thinking and reflective action) which supports reflective learning and practice and supports educators to look at issues through multiple lenses using 'reflective activism’ (Brookfield 1987; Hanson, 2012; Hanson and Appleby 2015, 31) to make decisions and solve complex problems.

\section{Freedom of Thinking and Mindfulness}

The discourse about critical thinking has developed further within the current era of emphasis on delivery of high quality service provision. There is considerable pressure placed on educators to meet targets, set goals and manage a myriad of issues concerned with taking a holistic approach to children and families' education and welfare within an arena of diminishing resources. In order to achieve this, educators require the skills to think, gather information, perceive the world around them, and change their perspective to reflect the needs of the situation. This is characterised as a mindfulness approach which according to Capel (2012), involves awareness, and open-minded acceptance of the current situation while paying attention to the inner feelings this engenders without rushing to judgement and action (Weare 2013). Such an approach lends itself to a freedom of thinking which allows issues to be viewed without pre-conditioning and to be seen through a clearer lens (Shapiro and Carlson 2009). It also advocates a caring, emotionally empathetic and emotionally intelligent approach (Goleman 2005). Mindfulness has a part to play in developing the self-regulation of emotions necessary to manage complex situations in the moment. It means being able to ground oneself and regulate one's attention within the actions being pursued (Bishop et al. 2004). This must, however, be tempered with a note of caution. This is a comparatively new way of thinking and acting 
and misconceptions as to definition and use may in the words of Purser and Milillo (2014, 9) render the approach an 'ethically neutral performance enhancement technique.' Within professional life, mindfulness can lead to increased sensitivity in understanding and using the cues available in a non-reactionary manner to choose the most appropriate response (Baer and Lykins 2011). Understood in this way, mindfulness can facilitate effective critical thinking (Noone, Bunting and Hogan 2016).

Within early childhood this is encapsulated by Competence Requirements in Early Education and Care (CoRe) $(2011,21)$ as in joining a ‘competent system’ of promoting learning and critical reflection the educator needs the ability to stand back and engage at the same time. Engagement with elements of mindfulness allow educators to develop their personal and professional identity in being aware of their own inner feelings and being able to utilise these in responding to complex, in the moment situations which are part of the daily life of educators.

\section{Critical Thinking and the Need for Self-Actualisation}

Critical thinking, which incorporates mindfulness, cannot be complete without an understanding of the dispositions to use these attributes, a belief in oneself and ability to take responsibility and control over events that affect one's life. Throughout a course of learning within the Foundation Degree, such capabilities and skills are fostered and nurtured. Maslow's (1943) hierarchy of needs can lend itself to an examination of student progress through gaining security to try out new ideas, gaining self-esteem through achievement, mastery of new skills and social approbation, learning how to learn, collaborating as part of a community of practice: all of which lead to self-fulfilment and increasing independence (Reed, Tyler and Walker 2015). Such skills are important to deal with adversity, challenges and inequalities which are ever- present in professional life in 
Early Years. The relationship between critical thinking has been further explored by Jarvis et al. (2003) who, taking a humanistic approach, see critical reflection as the outcome of critical thinking which then promotes self-actualisation. Dodds (2001) urges students to move through a 5 stage model of competence leading to self actualisation with critical reflection being key to success.

Empowering students to use their learning and understanding of self through reflection to move towards successful futures is key in the development of self-actualisation (Bandura 1994). Coming to know oneself within and through the changing personal and professional landscapes, having a strong value base and reflecting on the wider issues for practice, lifelong learning and the building of communities of practice are a strong basis for success (Opengart and Short 2002). Using the different capacities of students, the aim of the Foundation Degree is to enable students to find their voice and to best represent it to advocate for the child, family and the Early Years profession, ' to envisage a world that is not yet' but may emerge in the future (Simon 1987, 395.)

\section{Research aims and Programme}

The research aimed to seek the views of alumni on the way a university programme of professional development has influenced an acquisition of critical thinking, mindfulness, and self-actualisation through development of their own personal and professional experiences and learning. Having gained insights from this, to see how this could inform the instructional design of the Foundation Degree course.

The programme under consideration is a Foundation Degree (Early Education) delivered in England through 4 partner Further Education Colleges across 7 campuses and a flexible and distributed route. It is validated through the university and has been in existence since 
2003. It covers all aspects of early years including quality provision, leadership, construction of childhood, enabling environments, planning, safeguarding, reflective practice and curriculum. It culminates with a small-scale practice based enquiry. The programme is delivered three years part-time, two full-time offering evening and day attendance. Completion of the programme provides entry to a several BA (Hons) Top up degrees, and after this progression to Early Years Initial Teacher Training and Postgraduate Certificate in Education (PGCE). Students come from workplaces in urban and rural settings that are socially diverse. Internal and external institutional review processes confirm the programme meets national quality requirements, is well managed and addresses the needs of students and employers.

The programme structure estimates and supports patterns of learning, from active induction to guided exploration, which requires a student to make an independent creative contribution, becoming a self-organised learner (Reed 2015). Modules are carefully designed to support praxis, incorporate study skills, encourage reflection on practice, promote transferable skills and an ethical value base. Students are supported and encouraged to work collaboratively within an Appreciative Enquiry stance (Cooperrider 2005). Assessment is carried out through a range of summative assignments, which are designed to raise professional confidence and competence in terms of shaping practice and making a difference to the lives of children and families (Walker and Reed 2015). Qualities that students are encouraged to develop include negotiation, communication, leadership and reflective questioning. Students from all partnership colleges are brought together for an annual conference in which tutors and students participate through workshop leadership and through an annual study day held at the university. Work based 
learning is integrated through a series of formative tasks carried out within the workplace and is competence is assessed at each level of study through a portfolio.

\section{The Research Design}

The methodology adopted a collaborative, qualitative approach. Participatory qualitative research that works 'with 'and not 'on' alumni was used, thus ensuring that the researcher is not seen as the expert but as working together with participants. It enabled the participants to become co-researchers as part of a focus group in a safe uninterrupted space to consider their interpretation of their learning journey as critical thinkers and its usefulness for their practice. This approach allowed data collection from participants who are engaged in thinking about professional situations, understanding and improving their response and reflecting on the consequences and impact of their work (Ghaye et al .2008). In this case, to collaborate in understanding how critical thinking enhances professional practice and how it is developed (Reason 1999; Reason and Riley 2008). This lends itself to an approach where purposeful relationships are in place as a starting point from which to explore the issue. In the case of the alumni, the researcher was both an insider and an outsider to the process (Costley, Elliott and Gibbs 2010). The researcher had established relationships with the group as a tutor over the three-year period of their degree and had remained in contact with several members of the cohort group on a professional basis since the completion of their degree. This meant that there was a relationship already established with an element of trust between the parties from which to work thus mitigating against potential 'academic - practitioner divide' (Shani et al. 2007). This approach lends itself to the small group arena and starts from the current practice issues of interest within the professional lives of the participants. Ethically the approach encompasses the examination of a worthwhile purpose for the community of 
practice of which the researcher and participants are a part and as such is grounded within daily experience and practice. It allows the participants to tell their stories, integrate these with theory, and reflect upon them and to make sense of these to further understanding (Reason 2006). However, in order to ensure that my position as an insider meant that I did not let my professional relationship cloud the data, I asked all participants to read the transcript and confirm that it was a true record of what they said before writing up the data for the paper. The participants also checked the draft paper before it was sent for review.

This group were invited to participate because they had completed their studies three years previously. This was judged not too long to have forgotten the experience of undertaking the degree but long enough ago to have made use and given time to the consolidation of their learning and be able to reflect upon their journey as critical thinkers. The cohort comprised 18 students and all were invited to attend the focus group. Seven replies were received and of this, 6 participated in the research. All of the participants were female between the ages of $30-60$, all except one married with children. The research took place over the period of a year. Although this is a small sample and generalisations cannot be extrapolated, it does provide an in depth discussion of critical thinking from which some valuable insights have been gained. The sample was chosen to represent the make-up of the cohorts studying the Foundation degree at the university which despite best efforts tend to be predominately-mature females. Agreement to participate was gained by letters of consent.

The university ethics committee agreed ethical parameters of the research. As a lone researcher, it was important to have a critical friend and a colleague from the Foundation Degree undertook to carry out this role. She did not participate in the focus group but has 
given valuable advice about the design of the research and insights into data analysis from her examination of the transcript.

The method of data collected used was a focus group that took place at a time convenient to the participants and was one and a half hours in length. This method was chosen in order to gain the views of the participants within a rich discussion of the student journey. It enabled depth of authentic discussion but within an interpretive approach could lend itself to researcher bias. This was mitigated by asking participants to confirm the transcript as a true representation of what they said and through the help of a critical friend. Some prompt questions informed by literature review were provided to initiate the discussion. These included:

What has been your professional journey since starting the degree?

Do you think the degree had any impact upon this and if so what was this?

Can you give any examples of how your thinking has developed during the degree and subsequently?

Has the degree had an effect on you personally? If yes what is this?

What skills and dispositions do you think are needed to become a critical thinker?

Permission was sought to record the group. Participants clearly understood the research aims prior to agreeing to attend. There were no withdrawals from the process by any of the alumni. At the outset, it was made clear that the discussion would include aspects of personal development because of their higher education experience and some time was spent in reconnecting the group and ensuring that the participants were comfortable with this aspect. The focus group began by the researcher asking the participants what their personal and professional journey had been since finishing the degree.

The data gathered was transcribed, interrogated and coded into research themes. Each participant was given a pseudonym and the number of times each spoke was counted to 
show the level of participation The transcript was read several times and comments that did not relate to the issues removed. The content was colour coded into themes relating to critical thinking, mindfulness, self-actualisation and impact of the degree in practice. These were represented on a reduction grid indicating which participant made the specific comments and how many times this occurred throughout the duration of the focus group. The original transcript was reviewed by the critical friend and subsequent discussion revealed that similarities of themes emerged. These included: engagement with the world of practice and impetus for critical thinking, personal learning identity, self-direction, problem solving, questioning learning, self-sustaining practices and goals, standing back and engaging reflectively with learning, a belief in oneself and ability to take responsibility and control over events that affect one's life and having a strong value base. The data suggested that success comes through acquiring these attributes, coming to know oneself and envisioning a world where children and families have a voice that is both heard and actioned.

\section{Findings and Discussion}

The participants of the focus group all took time at the outset to explain their progress since completing the Foundation Degree. Four had completed further study and had achieved their BA degrees and three had achieved Early Years Initial Teacher Training qualifications. Two are currently completing Masters Degrees. All had become leaders or managers, holding positions of authority within their settings and attested to their qualifications having been influential in their career trajectory.

It was evident within the discussion that there were important underpinning aspects of their student learning that developed throughout the degree as precursors to critical thinking. These included the alignment between theory and practice, becoming 
researchers in their own right, understanding reflective practice and the role these play in confidence building. These were fostered through building dynamic discussion spaces. Phillips and Bond's (2004, 293) notion of developing an 'institutional culture of inquiry' where there is a safe space to explore issues rather than a direct embedding of critical thinking skills into the curriculum.

We had our cohort and the dynamic of being able to explore issues on small tables and with a cohort that for a while works together and this really is good about FdA. We often went off on a tangent but the discussions were deep. I miss that now (Bethany) Real world formative activities and summative assessments allowed for the testing out of ways of working and subsequent critical evaluation with peers and tutors within a safe space. The chance to undertake problem based learning and small-scale practice based enquiry was cited by all participants as instrumental in their developing confidence, analytic skills and knowledge. Participants said:

We have to analyse who came to our groups and what service was offered eg advice and guidance and everything goes into the data system so when Ofsted come they can see what we have done. It has to be evidenced based information. The independent studies taught me to analyse what I am saying much more. (Claire)

The degree is about making your own decisions based on what you know and analysis and critiquing what you see and what you know and putting the two together. It makes you forge your own opinions within the remits about trying new ways based on research (Bethany)

Participants perceived themselves as researchers; having developed a spirit of enquiry and critical approach to their work. Through collaborative action research, learning choice and reflection self-confidence has emerged and this has been sustained into practice as they continue to develop areas of small-scale research when faced with 
seemingly insoluble issues. Professional and personal confidence was seen to be the bedrock of their journey. This was expressed in several ways and seen as the springboard from which to develop critical thinking. The stories told by the participants during the focus group about their experiences were described as 'pegs on which to hang critical thinking'

When considering the nature of their confidence, the participants considered that it is comprised of a number of elements. Firstly, through being assertive and being able to own decision-making despite potential adversity from colleagues or other professionals:

We find a problem with the 6 week summer holiday as a lot of reception teachers do not accept our judgement about what we say for the children at the end of the preschool year. That we end up being told that we have over egged their ability and that we are not at a point where we can assess them at this level. The degree has made me confident to say that children have reached these levels and to stick to my guns (Anna) I have more confidence because I am a practitioner in my own right. I can hold my own in a room full of people who have a wealth of knowledge (Davina)

Confidence was represented through the ability to support others and to be able to try new ways of working and to take risks and allow others to take risks.

You don’t mind if something does not work and you say to staff if something does not work, we will try something else. They feel relaxed because I am and they are supporting one another (Eva)

Let's try something different .You can put a little seed in and see the staff blossom. The degree gives you confidence to support others even if they are not taking the qualification themselves and expanding the way they think. Cascading understanding. You need your own experiences to do this (Anna). 
Confidence also came through the acquisition of knowledge and having an underpinning theoretical basis on which to draw. One participant in discussing supporting a colleague talked about introducing the hierarchy of needs (Maslow 1943)

I was pleased I had this knowledge there that you don’t forget but you don't use every day and lots of things have come up like that over time and it just pops up and I realise it has come from the degree (Eva)

In identifying what needs to be in place for critical thinking to develop, confidence, along with trust and collaboration, were seen as essential features needed to be able to think differently and to penetrate deeper layers of thinking. Being able to look at issues from different perspectives through reflective practice was a feature developed through the degree study and seen as a pre-requisite to critical thinking.

I was reflective but did not have a name for it and understanding what it is and giving a name to it and understanding the process and what it entails and how you go about it makes it real and ok to say right I have done this let's think about it - there is actually a process to it not just me changing my mind and you have to unpick the process and not just understand it (Bethany)

It would seem then that the interplay of confidence within its various forms of expression: reflective activism, learning through problem solving engagement with the field and acquiring knowledge, finding a voice, striving for ethical practice and professional and personal identity within a community of practice all have a part to play in the journey to becoming a critical thinker (Ortlipp, et al 2011; Sheridan 2009; Worsley and Lamond 2014; Capel 2012). However, the participants assert these are not enough to sustain critical thinking beyond the achievement of a degree or qualification. The data suggests there needs to be an impetus that drives practitioners and educators to continue to develop and sustain this practice. In terms of early years, this is an overriding need to put children 
and family needs at the heart of practice. Furthermore, to ensure that these are met in order for the child to have the best experience possible and to maximise outcomes.

The reason I did the degree was to become a better practitioner for families. Critical thinking develops because you are putting the child at the heart of your practice and this is the impetus for developing criticality (Anna)

We cannot lose sight of our remit or vocation that is about the child and we have to have that understanding at the heart of all we do (Emily).

Being an advocate for children and families who may struggle to find their voice or may be vulnerable due to a myriad of reasons is a key part of early years practice. The Early Intervention agenda (Allen 2011) places early years in a unique position in terms of knowing their families well and being able to offer help early before a family situation reaches crisis point. The responsibility of this position was keenly felt by all the participants who strive to fully understand needs and to keep the child at the forefront of practice. This is the driver of their ability to think critically to find often-creative solutions.

You feel parents think you are the expert. We get that a lot with parents and health visitors who refer and assume we will fix the child. We have to use all our skills to think of solutions and then work with the parent to manage change (Claire) The children's needs as a starting point for practice involve an ability to juggle a number of roles. Participants cited being, social workers, substitute parents, speech and language therapists, teachers, counsellors as among the many parts they play. The participants agreed that this was an important part of developing the professionalism of Early Years. This requires an ability to think differently- to go underneath the layers, being able to 
analyse, pick things apart but also, importantly to represent the child's voice. Critical thinking means understanding the view of the child and incorporating this into thinking and planning.

Asking the right questions (Anna)

We have to see ourselves as upskilling and enriching the system around the child (Bethany)

The impetus to develop sustainable critical thinking involves understanding the complexity of Early Years and at the point when this becomes apparent, critical thinking is truly in place.

When you understand the complexity of Early Years you are there and you will never stop learning and appreciating the complexity. The future will not be finite and your criticality will go on developing but believing in yourself is key (Frances) Such understanding comes through the degree having given the participants the ability to think differently, through a confident understanding of themselves as practitioners with a strong ethical value base, clear purpose to their practice and personal abilities to stand back, to reflect, and use their own experiences and learned knowledge to further the potential of children and families. This has elements of Barnett's (1997) axial approach where the interplay of operational critical thought, retelling of traditional courses of action and thinking to transform learning, knowledge and personal input leads to critical thinking and action. Participants talked about some of the successful interventions they had made based on experience, knowledge and thinking creatively using their personal and professional skills to think critically about situations and effect a successful resolution. 
This was evident throughout the intensity of their discussion, by not only what they said but through the passion with which they debated the issues raised and recounted stories of how they had dealt with recent complex issues. They had all worked a full day, juggling a myriad of issues but the sustained energy of their critical response and engagement with the group discussion was remarkable. This belies Gibb’s (2002) notion that the Foundation Degree may not encourage the critical thinking developed through other more traditional university degrees.

The knowledge we gained from the course and each other was invaluable. The discussions got really in depth and were long.

The discussion reflected a strong value base where ethicality in dealing with children and families is at the forefront. This becomes part of everyday personal and professional life and suggests that educational change and learning begins in people's minds as they 'make choices about which values to espouse and how to live in the direction of those values' (McNiff and Whitehead, 2002: 11).

When I am talking to schools or have a conversation with a setting I am able to speak from the child's voice and suggest that people look more closely at what the child needs.

However, critical thinking within this current landscape of practice is not enough: elements of mindfulness are essential to incorporate into this process to develop the participants’ personal identity as agents of change.

You have to think on your feet and react on your feet very quickly every day - the amount of times we do that is quite scary to add up (Davina) 
This discussion of managing complex situations meant that for the participants there was a need for them to be aware of their emotions and to use these in formulating a response. Alongside this, to be able to regulate and assimilate these with the verbal and non-verbal cues within the situation, their own knowledge both practical and theoretical and the needs of those involved to formulate an effective response. The potential complexity within day-to-day issues requires the educator to understand situations that arise in the moment and may require prompt action. They need to be able to use all the verbal and nonverbal information at hand to sum up and come to a decision on the action needed (Bishop et al.2004). This often means the processing of information, reviewing the alternatives and importantly understanding and managing one’s own viewpoints and emotions through self-regulation that allows critical thinking to emerge (Noone, Hunting and Hogan 2016,). This resonates with Gibbs (200) assertion that it is not the curriculum that is important but the way that it is shaped and used for future practice. The inclusion of real world practice based scenarios and problem tasks lend themselves to developing the skills necessary for future practice. Thus, the process of the degree becomes as important as the outcome in terms of the development of critical thinking. However, it is the impact of the outcome that must also be considered for those involved in ensuring that the needs of children and families are effectively met and that they are empowered as part of this process.

This implies developing a value based professional identity that is empowered through a mindfulness approach in order to be a successful advocate for children. Without an ability to be self- reflective, open minded, pay attention to the inner child and to stand back before making assumptions, the level of criticality to unpick complex situations and needs are potentially comprised (Weare 2013). Being in the position of dealing with the ever changing and deepening complexities of Early Years means that practitioners are at the 
forefront of advocating for the child. This gives a unique sense of professional and personal responsibility that transcends qualification, status and low financial reward and which involves a sense of purpose, passion and validation through personal connection and sense of fulfilment. This sense of knowing oneself and one's contribution and being able to articulate this through mindfulness, underpinned by evidenced based knowledge and a set of beliefs and attitudes about childhood affords self-actualisation as a critical thinker.

Being an advocate for children and families, speaking up on their behalf sometimes at personal cost to themselves perhaps gives an authority, a sense of responsibility for one's actions: finding self - actualisation in guiding children and families to their own sense of future success.

I think part of it is understanding Early Years as a whole picture you do not do it for the money and you don't do it to be on a pedestal. You want recognition and be respected and working as a team but you want to do the best for children and families and enjoy it. (Davina)

The desirable future is not one that includes status but one where children and families succeed through the support given at the setting. The personal and professional practice shown by the participants forges an aspiration to change views and practice within the community of practice so that children have a positive experience and move on to the next stage of their learning with confidence and a sense of self-esteem. Selfactualisation comes through using one's learning, experience and knowledge to do the best possible for each child. 


\section{Implications and Limitations}

This was a small-scale piece of research with a limited number of participants, all of whom were experts in their field. However, whether this could be replicated is questionable as it is a specific case rather than a broad application. It may well be that a reason some alumni did not respond was that their career trajectory may have been less successful, although data gathered as a part of university student destinations indicate that this may not be the case but nevertheless it must be counted as a factor. Its strength lies in the focus group being able to provide rich data to add to the discourse of the learning journey in making a transition to being a critical thinker and the implications of this for early childhood professional practice. This in turn has implications for the instructional design of foundation degree courses within the field in understanding that the impetus for making the transition lies within a position of mindfulness that places children and families’ needs for achieving positive outcomes at the forefront of critical thinking.

The implications of this for future design of the Foundation Degree are far reaching. It is perhaps difficult to come to an absolute definition of what critical thinking is as this develops as the landscape of Early Years changes within the wider context of society. Within this, the role of the degree is to establish critical thinking through a cycle of theoretical understanding, asking questions, application, demonstration, construction and re-construction of knowledge, self- directed learning and reflection, analysis of own thinking and decision making processes both within academia and practice. This reflects Gibbs (2000) argument that it is not the curriculum that is important but how it is shaped by the academic community. Also, it could be argued, how it is shaped in consultation with the practice community and used for future practice.In terms of pedagogy, however, the degree should perhaps enhance personal and professional learning, becoming practice led and rooted in practice based enquiry, practice based learning and real world problem 
based learning. This would require negotiation with settings by the student and university to ensure that it is possible for students to gain experience to both acquire and construct knowledge within the workplace at a pace that the setting can manage and see as beneficial to children and families. Critical thinking becomes of paramount importance within evaluation of the impact of the work for children and families and setting. For policy makers within education and care, this research would indicate that critical thinking skills, incorporating mindfulness need to be an integral part of instructional design at all levels of teaching and learning programmes. Continuing discourse is needed to enhance the currency of programmes in meeting the diverse and complex needs of children and families. Moreover, each academic programme may need to identify the impetus inherent within their subject, which acts to sustain critical thinking into future employment and self-actualization of participants as they develop their career paths. Within the current agenda of promoting the wellbeing of children and practitioners, it is useful for policy makers to consider what constitutes self-actualization for the workforce within early years and the broader field of education.

\section{Conclusion}

The elements of critical thinking within early years professional and personal practice have been explored and to some extent resonate with the thinking of theorists discussed within the literature review. Critical thinking requires pre-requisites of confidence, research skills and reflective practice. It further needs an impetus to drive its sustainability beyond an academic arena. It needs elements of mindfulness in its implementation. Taken together this represents a sense of self-actualisation for professional practice, which may serve to sustain practitioners over the course of their career and to meet the requirements of the ever-growing complexity of the professional landscape. However, further research 
is required with a greater sample of students and graduates in order to test the validity of this very small scale piece of research.

My thanks go to the alumni who took part in the research. Also to my critical friend, who helped me to develop this paper.

\section{Disclosure Statement}

No potential conflict of interest was reported by the author

\section{References}

Allen, G. 2011. Early Intervention: The Next Steps. HM Government. https://www.gov.uk/government/uploads/system/uploads/attachment_data/file/284086/e arly-intervention-next-steps2.pdf

Bandura, A. 1994. "Self-Efficacy.” In Encyclopaedia of Human Behaviour edited by Ramachaudran, V.S.E, 71 - 81. New York: Academic Press.

Barnett, R. 1997. Higher education: A critical business. Buckingham: Society for Research into Higher Education and Open University Press.

Baer, R., and E. Likens. 2011. “Mindfulness and Positive Psychological Functioning.” In Designing Positive Psychology: Taking Stock and Moving Forward edited by Sheldon, A., Kasdan, T., and Steger, M. 335 -351. Oxford: Oxford University Press.

Bishop, S.R., M. Lau, S. Shaperio, L. Carlson, N.D. Anderson, J. Carmody, Z.V. Sega, S. Abbey, M. Speca, D. Velting, and G. Devins. 2004. "Mindfulness: A proposed operational definition." Clinical Psychology: Science and Practice 11 (3): $230-241$.

http://www.personal.kent.edu/ dfresco/mindfulness/Bishop_et_al.pdf

Brookfield, S. D. 1985. Self-directed learning: From theory to practice. New directions for continuing education, no. 25. San Francisco: Jossey-Bass.

Brookfield, S. D. 1987. Developing critical thinkers: Challenging adults to explore alternative ways of thinking and acting. Milton Keynes: Open University Press.

Callan S., M. Reed, and S. Smith. 2012. “A pedagogy for educating 'new professionals." In Debates on Early Childhood Policies and Practices: Global Snapshots of Pedagogical Thinking and Encounters, edited by T. Papatheodorou, 97 - 104. London: Routledge. 
Candy, P. 1991. Self-direction for lifelong learning. San Francisco: Jossey Bass.

Capel, C.M. 2012. "Mindlessness/mindfulness, classroom practices and quality of early childhood education: An auto-ethnographic and intrinsic case research.” International Journal of Quality. \& Reliability Management 29 (6): 666-680.

Coffield F., D. Moseley, E. Hall, and K. Ecclestone. 2004. Learning styles and pedagogy in post-16 learning: a systematic \& critical review. London: Learning Skills Research Centre.

Cooperrider, D. 2005. Appreciative Inquiry: A Positive Revolution in Change. San Francisco, CA: Berrett-Kochler.

CoRE. 2011. Competence Requirements in Early Childhood Education and Care. European Commission, Directorate General for Education and Culture Final Report. University of East London, Cass School of Education and University of Ghent, Department for Social Welfare Studies. September 2011.

https://download.ei-ie.org/Docs/WebDepot/CoReResearchDocuments2011.pdf.

Costley, C., G. Elliott, and P. Gibbs. 2010. Doing Work Based Research: Approaches to Enquiry for Insider Researchers. London: Sage.

Cranton, P.A. 1994. Understanding and Promoting Transformative Learning. San Francisco, CA; Jossey Bass.

Dewey, J. 1933. How we think: A restatement of the relation of reflective thinking to the educative process. Lexington, MA: Heath.

Dodds, A.2001. "From Survival to Self-Actualization: Reflections on Teaching and Teacher Education.” The High School Journal, 84 (3) 13-18. https://muse.jhu.edu/article/13868

Ghaye, T., A. Melander - Wikman, M. Kisare, P. Chambers, U. Bergmark, C. Kostenius, and S. Lillyman, 2008. "Participatory and appreciative action and reflection (PAAR) - democratizing reflective practices.” Reflective Practice 9 (4): 361-397.

Gibbs, P.T. 2000. “Isn't higher education employability?” Journal of Vocational Education and Training 52 (4): 559-571.

Gibbs, P.T. 2002. "Who Deserves Foundation Degrees?” Journal of Further and Higher Education 26 (3): 197-206.

Goleman, D. 2006. Emotional Intelligence. New York: Random House.

Hanson, K. 2012. Supporting the Development of Reflective Dispositions for Professional Practice. http://tactyc.org.uk/pdfs/2013-conf-Hanson.pdf 
Hanson, K., and K. Appleby. 2014. "Reflective Practice.” In A Critical Companion to Early Childhood, edited by M. Reed, and R. Walker, 24 - 35. London: Sage.

Jarvis, P., J. Halford, and C. Griffin. 2003.The Theory and Practice of Learning. London: Kogan Page.

Jung, C.G. 1971. Psychological Types. Princeton, NJ: Princeton University Press.

Knapper, C.K., and A.J. Cropley. 1991. Lifelong Learning and Higher Education. 2nd edition. London: Kogan Page.

Kolb, D.A. 1984. Experiential Learning. Englewood Cliffs, NJ: Prentice-Press.

Kreber, C. 1998. "The relationships between self-directed learning, critical thinking, and psychological type, and some implications for teaching in higher education.” Studies in Higher Education 23 (1): 71-86.

MacNaughton, G. 2001. “Action Research.” In Doing Early Childhood Research: International perspectives on theory and practice, edited by G. MacNaughton, S.A.Rolfe and I. Siraj-Blatchford, 208-223. Crows Nest, New South Wales: Allen \& Unwin.

Maslow, A.H. 1943. “A Theory of Human Motivation.” Psychological Review, 50 (4): 370 -396. http://psychclassics.yorku.ca/Maslow/motivation.htm.

McNiff, J., and J. Whitehead. 2010. Action Research: Principles and Practice. $2^{\text {nd }}$ edition. London: Routledge.

Meizrow, J.1985. “A critical theory of self-directed learning.” In Self-directed Learning: from theory to practice, New Directions for Continuing Education no. 25, edited by S.Brookfield, 17-33. San Francisco, CA: Jossey-Bass.

Mezirow, J. 1991. Transformative Dimensions of Adult Learning. San Francisco: Jossey Bass.

Noone, C., Bunting, B., and Hogan, M.J. 2016. "Does Mindfulness Enhance Critical Thinking? Evidence for the Mediating Effects of Executive Functioning in the Relationship between Mindfulness and Critical Thinking.” In Frontiers in Psychology.19 http://journal.frontiersin.org/article/10.3389/fpsyg.2015.02043/full

OECD. 2006. Starting Strong II: Early Childhood Education and Care. Paris: OECD.

OECD. 2011. PISA in Focus Nr. 10: What Can Parents do to Help their Children Succeed in

School? Paris: OECD.

OECD. 2012. Quality Matters in Early Childhood Education and Care: United Kingdom

(England). Paris: OECD.

Opengart, R., and D.C. Short. 2002. "Free Agent Learners: The New Career Model and Its Impact on Human Resource Development.” International Journal of Lifelong Education 21: 220-233. 
Ortlipp, M., L. Arthur, and C. Woodrow. 2011. "Discourses of the early years learning framework: constructing the early childhood professional.” Contemporary Issues in Early Childhood 12 (1): 56-70.

Purser, R., and J. Milillo. 2014. "Mindfulness Revisited: A Buddhist-Based Conceptualization.” Journal of Management Inquiry 24 (1): 3-24.

QAA. 2010. Foundation Degree Qualification Benchmark.

http://www.qaa.ac.uk/en/Publications/Documents/Foundation-Degree-qualificationbenchmark-May-2010.pdf

Phillips, V., and C. Bond. 2004. "Undergraduates' experiences of critical thinking.” Higher Education Research \& Development. 23 (3): 277-294.

QAAHE. 2015. Foundation Degree Characteristics.

http://www.qaa.ac.uk/en/Publications/Documents/Foundation-Degree-Characteristics15.pdf.

Ramsden, P., and E. Martin. 1996. "Recognition of good university teaching: policies from an Australian study.” Studies in Higher Education 21: 299-315.

Reason, P. 1999. "Integrating action and reflection through co-operative inquiry.” Management Learning 30 (2): 207-27.

Reason, P. 2006. “Choice and Quality in Action Research Practice.” Journal of Management Inquiry 15 (2) 187-203.

Reason, P., and S. Riley. 2008. “Co-operative Inquiry. An Action Research Practice.” In

Qualitative Psychology - a practical guide to research methods edited by J. Smith, 207234.

London: Sage.

Reed, M. 2015. “A provocation examining ways to articulate the voice of early childhood

practitioners.” Paper presented at the European Early Childhood Education Research

Association conference (ECEERA) Barcelona, Innovation, Experimentation and Adventure in Early Childhood. Universitat Autónoma de Barcelona, Barcelona, Spain September 7 - 10.

Reed, M., L. Tyler, and R. Walker. 2014. “Developing the undergraduate Journey.” In A Critical Companion to Early Childhood edited by M. Reed, and R. Walker, 15 22. London: Sage.

Sedlak, C. A., M.O. Doheny, N. Panthofer, and E. Anaya. 2003. "Critical thinking in students' service-learning experiences.” College Teaching 51(3): 99-103.

Shani, A.B., S.A. Mohrman, W.A. Pasmore, B. Stymne, and N. Adler. 2007. "The promise of collaborative management research.” Handbook of collaborative management research edited by. A.B. Shani, S.A. Mohrman, W.A. Pasmore., B. Stymne, and N. Adler, 7-32. Thousand Oaks, CA: Sage.

Shapiro, S.L., and L.E. Carlson. 2009. The Art and Science of Mindfulness: Integrating Mindfulness Into Psychology and the Helping Professions. American Psychological Association. http://dx.doi.org/10.1037/11885-001. 
Sheridan, S.M., C.P. Edwards, C.A. Marvin, and L.L. Knoche. 2009. "Professional Development in Early Childhood Programs: Process Issues and Research Needs.” Nebraska. Center for Research on Children, Youth, Families and Schools, University of Nebraska - Lincoln Early Educ Dev 20 (3): 377-401.

Simon, R. 1987. "Empowerment as a Pedagogy of Possibility.” Language Arts 64 (4): $370-382$.

Stronach I., B. Corbin, O. McNamara, S. Stark, and T. Warne. 2002. "Towards an Uncertain Politics of Professionalism: Teacher and nurse identities in flux.” Journal of Education Policy 17(1): 109-138.

http://dx.doi.org/10.1080/02680930110100081.

Walker, R., and M. Reed. 2016. Making Practice Visible. Presentation at SEFDEY National Conference.

Weare, K. 2013. "Developing mindfulness with children and young people: a review of the evidence and policy context.” Journal of Children's Services.

https://mindfulnessinschools.org/wp-content/uploads/2013/03/children-andmindfulness-journal-of-childrens-services-weare.pdf.

Weiner, B. 1986. An Attributional Theory of Motivation and Emotion. New York: Springer Verlag.

Worsley, J., and C. Lamond. 2014. “Critical Thinking.” In A Critical Companion to Early Childhood edited by M. Reed, and R. Walker, 48 -57. London: Sage.

Zembylas, M. 2005. “Discursive Practices, Genealogies, and Emotional Rules: A poststructuralist view on emotion and identity in teaching." Teaching and Teacher Education 21, 935-948. http://dx.doi.org/10.1016/j.tate.2005.06.005

Table 1. Type your title here.

Figure 1. Type your title here. Obtain permission and include the acknowledgement required by the copyright holder if a figure is being reproduced from another source. 